Article

\title{
Comparative Study of Water-Leaching and Acid-Leaching Pretreatment on the Thermal Stability and Reactivity of Biomass Silica for Viability as a Pozzolanic Additive in Cement
}

\author{
Weiting $X u^{1, *} \mathbb{C}$, Jiangxiong Wei ${ }^{1, *}$, Jiajian Chen ${ }^{2}$, Bin Zhang ${ }^{1}$, Peng $X u^{3}$, Jie Ren ${ }^{4}$ \\ and Qijun Yu ${ }^{1}$ \\ 1 School of Materials Science and Engineering, South China University of Technology, Guangzhou 510641, \\ China; mszhangbin@mail.scut.edu.cn (B.Z.); concyuq@scut.edu.cn (Q.Y.) \\ 2 Department of Civil Engineering, Foshan University, Foshan 528000, China; chenjiajian@fosu.edu.cn \\ 3 Department of Mechanics and Civil Engineering, Jinan University, Guangzhou 510632, China; \\ t60at3@gmail.com \\ 4 Department of Infrastructure Engineering, The University of Melbourne, Melbourne, VIC 3010, Australia; \\ renjie630@gmail.com \\ * Correspondence: xuweiting@scut.edu.cn (W.X.); jxwei@scut.edu.cn (J.W.); \\ Tel.: +86-20-87110629 (W.X. \& J.W.)
}

Received: 2 August 2018; Accepted: 10 September 2018; Published: 12 September 2018

check for updates

\begin{abstract}
The present work aims to introduce a novel and eco-friendly method, i.e., a water-leaching pretreatment for extracting highly reactive biomass silica from rice husk ( $\mathrm{RH})$, for viability as a pozzolanic additive in cement. For comparison, the traditional acid pretreatment method was also employed throughout the experimental study. The silica from $\mathrm{RH}$ was extracted using boiled deionized water and acid solution as leaching agents to remove the alkali metal impurities, and then dried and submitted to pyrolysis treatment. The results indicated that potassium was found to be the major contaminant metal inducing the formation of undesirable black carbon particles and the decrease in crystallization temperature of amorphous RHA silica. The boiling-water-leaching pretreatment and acid-leaching pretreatment on RHs significantly removed the metallic impurities and reduced the crystallization sensitivity of RHA silica to calcination temperature. A highly reactive amorphous silica with purity of $96 \%$ was obtained from $\mathrm{RH}$ via $1 \mathrm{~N}$ hydrochloric acid leaching followed by controlled calcination at $600{ }^{\circ} \mathrm{C}$ for $2 \mathrm{~h}$. The acid treatments increased the crystallization temperature of silica to $1200{ }^{\circ} \mathrm{C}$ and retained the amorphous state of silica for $2.5 \mathrm{~h}$. In the case of water-leaching pretreatment, leaching duration for $2.5 \mathrm{~h}$ could yield an amorphous silica with purity of $94 \%$ and render the silica amorphous at $900{ }^{\circ} \mathrm{C}$ for $7 \mathrm{~h}$. The RHA silica yielded by water-leaching pretreatment presented a comparable enhancing effect to that of acid leaching on hydration and improved the strength of cement. Furthermore, compared with the acid-leaching method, the water-leaching pretreatment method is more environmentally friendly and easier to operate, and hence more widely available.
\end{abstract}

Keywords: amorphous silica; crystallization sensitivity; water-leaching pretreatment; rice husk ash; cement

\section{Introduction}

Rice husk $(\mathrm{RH})$ is the outer shell of the rice grain, which is a by-product of the rice milling process. It is an agricultural waste in all rice-producing countries. Most of the RH usually ends up either being 
dumped or burned in open spaces, which not only occupies a large land area but also represents a major source of contamination [1-3].

The major components of $\mathrm{RH}$ are organic materials such as hemicellulose, cellulose, and lignin, totaling about $85 \%$, and the remaining ash content is $15-20 \%$ [4]. Of all the residues of edible plants, the ash obtained from the calcined RH has the highest silica content [5]. The orthosilicic acid was ingested from soil and groundwater by the rice crop and further polymerized in the tissue structure of the plant, contributing to the formation of amorphous silica in the husk. After burning, $\mathrm{RH}$ becomes rice husk ash (RHA), which normally contains $85-95 \%$ of silica $\left(\mathrm{SiO}_{2}\right), 5-8 \%$ of alkali metal oxides, and some carbonaceous materials by mass [6].

Amorphous silica has a wide range of industrial applications, such as raw materials for ceramics synthesis, refractories, plastics, silica gels, silica chip, activated carbon and silica, catalysts, zeolites, ingredients for lithium-ion batteries, graphene, energy storage/capacitor, carbon capture, and drug delivery vehicles [7-17]. Compared with other industrial fields, the use of amorphous RHA silica in the production of concrete can realize large-scale consumption and reuse of waste, and hence eventually reduces the environmental impact due to improper disposal and land occupation. RHA is economical, widely available and highly reactive as a supplementary cementing material, due to its excellent physically filling and chemically pozzolanic effects [18-22]. It is also a promising substitute for replacing silica fume (SF) in high-performance concrete production.

Under a controlled calcination procedure and temperature, the calcination of $\mathrm{RH}$ removes hydrocarbon compounds and yields amorphous silica-rich powders with a large surface area. A highly reactive RHA silica is produced by burning $\mathrm{RH}$ at a temperature of $500{ }^{\circ} \mathrm{C}$ or lower for a comparatively protracted time under oxidizing environment or for a shorter time at a temperature of up to $70{ }^{\circ} \mathrm{C}$ [23]. The calcination of RH beyond this temperature may lead to the conversion of amorphous silica to crystalline silica polymorphs (quartz, cristobalite, and tridymite) [24]. Moreover, these crystals tend to predominate in unacceptable quantities and particle agglomeration may occur as the temperature increases, thereby reducing the chemical reactivity of RHA silica [25].

The temperature-sensitive nature of RHA silica leads to a rigid requirement for combustion instrument and pyrolysis technology, consequently capping the large-scale industrial production. To achieve amorphous silica ash of a desirable quality, a controlled combustion temperature and time are compulsory. Moreover, even if the RH is burned under controlled calcination conditions, the internal heat of the RH heap is difficult to release, and the temperature will rapidly exceed the crystallization point of the RHA silica. Thus, reducing the crystallization sensitivity of RHA silica to calcination temperature is the most critical issue for achieving large-scale production of biomass silica.

Studies indicate that the phase transformation temperature of RHA silica is markedly influenced by the inorganic chemical impurities [26]. Alkali metals, such as potassium, sodium, and calcium salts in $\mathrm{RH}$, preferably react with silica to form eutectic mixtures with low melting points. At a high concentration of potassium or sodium, the melting point of eutectic mixtures is as low as $600-700{ }^{\circ} \mathrm{C}$, significantly reducing the normal crystalline temperature of RHA silica [27].

The acid-leaching pretreatment on $\mathrm{RH}$ has been proved to be effective to remove the metallic contamination. The amorphous silica obtained from the acid pretreatment contains very high purity silica (above 95\%) [28,29]. However, the use of acid as a leaching agent usually causes corrosion in pipes and instruments, and increases the operational difficulty and production costs. Hence, it is of great importance to find a novel eco-friendly pretreatment method to remove metallic impurities from RHA silica.

In addition, the kinetics of the thermal stability of amorphous RHA silica under various leaching-pyrolysis treatments have not been clearly established. Moreover, major metallic contamination, which induces the amorphous silica in biomass $\mathrm{RH}$ compounds to crystallize at a relatively low calcination temperature, has not been verified.

In view of the fact that the biomass metallic salts are mostly soluble, this study explores using boiling water as a leaching argent for rinsing off alkali metal impurities in RHA silica and 
consequently obtaining a purified and highly reactive RHA silica. The present work aims to reveal the influence of water-leaching pretreatments on the crystallization behavior and chemical reactivity of RHA silica, consequently extending our knowledge for the industrialized mass manufacture and application of biomass silica. For comparison, the traditional acid pretreatment method is also assessed throughout the study. In this study, the effects of boiling-water-leaching pretreatment and acid-leaching pretreatment on crystallization sensitivity of RHA silica to pyrolysis conditions (calcination time and duration) were investigated and compared. The influences of metallic impurity and content on the thermal stability of RHA silica were identified by testing the crystallization behavior of the mixtures of purified RH and alkali salt. To examine the pozzolanic reactivity of the as-prepared RHA silica samples for their viability as a pozzolanic additive for the production of high-strength cement and concrete, the compressive strength, chemically bound water, and hydration product mineralogy of cement pastes with $10 \%$ cement replaced by RHA samples were examined.

\section{Materials and Methods}

\subsection{Materials}

Rice husk (RH) collected from a local rice processing plant (Academy of Agricultural Sciences Institute, Guangzhou, China) during the process of rice manufacturing was used as the starting material in this study. Commercially available chemical reagents, such as hydrochloric acid $(\mathrm{HCl})$, sulfuric acid $\left(\mathrm{H}_{2} \mathrm{SO}_{4}\right)$, and nitric acid $\left(\mathrm{HNO}_{3}\right)$, were of analytical grades and used as the acid-leaching agents for RH. Deionized water was used for the boiling-water-leaching pretreatment test as well as the residue rinsing of $\mathrm{RH}$ throughout the experiments.

\subsection{Leaching-Pyrolysis Treatment of $R H$}

$\mathrm{RH}$ samples were examined in this study by employing the leaching-pyrolysis steps. Two leaching pretreatment regimes, i.e., the boiling-water-leaching and acid-leaching pretreatment on $\mathrm{RH}$, were applied in this study to remove alkali metal impurities from RH.

In the case of boiling-water-leaching pretreatment, the RHs were weighed into three consignments of $10 \mathrm{~g}$ each. Each consignment was soaked in boiling water of $100{ }^{\circ} \mathrm{C}$ for $2.5,5$, or $10 \mathrm{~h}$, and then filtered and air-dried.

As for the acid pretreatment, RHs were weighed separately in three batches of $10 \mathrm{~g}$ each, and each batch was subjected to immersion in the acid solution (hydrochloric acid, sulfuric acid, or nitric acid) at a concentration of 1,2 , or $3 \mathrm{~N}$ acid solution for 1 or $2.5 \mathrm{~h}$ with constant stirring at ambient temperature. After the acidic solution was drained off, $\mathrm{RH}$ was rinsed with deionized water until the $\mathrm{pH}$ rose to 7 , then filtered and air-dried.

After the leaching pretreatments, the as-pretreated RH samples were collected and dried in a drying oven at $50{ }^{\circ} \mathrm{C}$ for $24 \mathrm{~h}$, and then separately subjected to pyrolysis in an electronic furnace for burning out at the desired temperature $\left(600-1200^{\circ} \mathrm{C}\right)$ until the appointed time $(0.25-2 \mathrm{~h})$. After the furnace hearth naturally cooled down to room temperature, the ash obtained was collected and subjected to grinding for $10 \mathrm{~min}$ in a laboratory mill. The ground ashes were kept separately in a desiccator for future material characterization tests.

The original $\mathrm{RH}$ was represented by $\mathrm{RH}$. In the case of acid-leached $\mathrm{RH}$, the $\mathrm{HCl}-\mathrm{H}_{2} \mathrm{SO}_{4}$, and $\mathrm{HNO}_{3}$-pretreated $\mathrm{RH}$ samples were marked as $\mathrm{Cl}-\mathrm{RH}, \mathrm{S}-\mathrm{RH}$, and $\mathrm{N}-\mathrm{RH}$, respectively. The boiling-water-leaching-pretreated RH samples were labeled W-RH. Accordingly, each RHA sample is named for clarification, e.g., 1Cl-RHA600-2h, which implies RHA with $\mathrm{HCl}$ leaching pretreatment for $1 \mathrm{~h}$ and then burning out at $600^{\circ} \mathrm{C}$ for $2 \mathrm{~h}$.

\subsection{Testing of $R H$}

Scanning electron microscopy (SEM) analyses were conducted to study the structure of acid-leaching- and water-leaching-pretreated $\mathrm{RH}$ samples at the micro level. The dried RH samples 
were coated with gold in a sputter coater. The SEM experiment was performed on a PHILIPS ESEM XL-30 (FEI, Hillsboro, OR, USA) operating at $20 \mathrm{kV}$ with a $15 \mathrm{~mm}$ working distance.

The functional groups in the RH samples were determined using an FTIR equipment BRUKER EQUINOX 55 (Bruker, Karlsruhe, Germany). The spectra were recorded with 32 scans at a resolution of $4 \mathrm{~cm}^{-1}$ in the range of $4000-400 \mathrm{~cm}^{-1}$.

\subsection{Testing of RHA}

\subsubsection{Characterization of RHA}

Quantitative chemical analyses of RHA were accomplished by X-ray fluorescence. The particle size was determined by the laser diffraction analyzer Easysize 20 (OMEC, Zhuhai, China). The surface area and pore volume of RHA were measured by Brunauer-Emmett-Teller (BET) and Barrett-Joyner-Halenda (BJH) methods, respectively, according to ASTM D3663-03 using Micromeritics Tristar 3000 Surface Area (Micromeritics, Norcross, GA, USA) and Porosity Analyzer (Micromeritics, Norcross, GA, USA).

The functional groups in the RHA samples were detected by the FTIR technique.

The pozzolanic reactivity of RHA silica was examined by the electrical conductivity change test, i.e., the reaction between RHA and a saturated calcium hydroxide solution. Each test utilized $200 \mathrm{~mL}$ of solution, which contained approximately $0.4 \mathrm{~g}$ of $\mathrm{Ca}(\mathrm{OH})_{2}$. Solutions were placed in a plastic Erlenmeyer flask and stirred at a constant temperature of $80^{\circ} \mathrm{C}$. Initial conductivity values were registered by a conductivity meter. Then, $5 \mathrm{~g}$ of RHA was added. $\mathrm{SiO}_{2}$ reacting with $\mathrm{Ca}^{2+}$ ions led to the formation of C-S-H, a non-conductive compound, and hence decreased the solution conductivity over time. The conductivity change value was recorded as an indication of the chemical reactivity of amorphous silica.

X-ray diffraction (XRD, Bruker, Karlsruhe, Germany) patterns were obtained using a Bruker MSAL XD2 X-ray Diffractometer using CuK $\alpha$ operated at $36 \mathrm{kV}$ and $24 \mathrm{~mA}$. The scanning two theta is between $10^{\circ}$ and $60^{\circ}$. EVA ${ }^{\mathrm{TM}}$ Software (Bruker, Karlsruhe, Germany) was used to record and analyze the structural pattern of the sample.

\subsubsection{Identification Tests for Metallic Contamination in RHA}

To identify the metallic trace element that leads to the decrease in crystallization temperature of RHA silica composites, the potential contaminant elements (the constituent trace elements of $\mathrm{RH}$ ) in terms of chlorine salts were separately incorporated into the $\mathrm{HCl}$-purified $\mathrm{RH}$. The trace element was incorporated into $\mathrm{RH}$ powder at a dosage of $2 \%$ by weight of the binder. The RH powder and chlorine salt were mixed for $1 \mathrm{~min}$ to obtain a homogenous powder mix. Then the mix was subjected to calcination at $600{ }^{\circ} \mathrm{C}$ for $2 \mathrm{~h}$ to yield an ash sample (silica composite).

To reveal the effect of potassium content on the crystalline behavior of silica in RHA, potassium in the form of $\mathrm{KCl}$ was incorporated into the acid-pretreated $\mathrm{RH}$ powder at five dosage levels of $0 \%, 0.5 \%$, $1 \%, 5 \%$, and $10 \%$ by weight of the binder. The binder of $\mathrm{KCl}$ and purified $\mathrm{RH}$ was mixed for $1 \mathrm{~min}$ to obtain a homogenous powder mix. Then the mix was subjected to calcination at 500 and $700{ }^{\circ} \mathrm{C}$ for $2 \mathrm{~h}$.

All the ash samples obtained were labeled and sealed separately in plastic bags for XRD characterization tests.

\subsection{Compressive Strength of RHA Incorporated Cement Paste}

The compressive strength of $20 \mathrm{~mm}$ mortar cube after three, seven, and 28 days of moist curing was determined in accordance with the ASTM C 311-07 standard. This test was carried out to examine the pozzolanic activity of the ash samples with various leaching pretreatments. One control mix (P0) and five pastes ((PR, P2.5WR, P5WR, P10WR and PCIR)) incorporating RHA obtained by calcining unpretreated $\mathrm{RH}$ or leaching-pretreated $\mathrm{RH}$ at $600^{\circ} \mathrm{C}$ for $2 \mathrm{~h}$ were prepared. $\mathrm{PR}$ is the paste incorporating RHA yielded by calcining unpretreated $\mathrm{RH}$ at $600{ }^{\circ} \mathrm{C}$ for $2 \mathrm{~h}$. P2.5WR, P5WR and 
P10WR represent the paste incorporating RHA obtained by 2.5, 5, and $10 \mathrm{~h}$ boiling-water-leaching pretreatment and calcining at $600^{\circ} \mathrm{C}$ for $2 \mathrm{~h}$, respectively; PCIR denotes the paste incorporating RHA obtained by $1 \mathrm{~h} \mathrm{HCl}$ leaching pretreatment and calcining at $600{ }^{\circ} \mathrm{C}$ for $2 \mathrm{~h}$. All the pastes were blended with $10 \%$ RHA by mass of cement and had a water binder ratio of 0.4 . The test yielded paste indicates the pozzolanic reactivity degree of RHA silica.

\subsection{Chemically Bound Water Content of RHA Incorporated Cement Paste}

To investigate the effect of the RHA silica on the hydration of cement matrix, a chemically bound water content test was conducted. After the compressive strength test, the broken paste fragments were selected and immediately immersed in anhydrous ethanol to stop cement hydration at the predetermined age. Then the fragments were baked in an electronic furnace at $105^{\circ} \mathrm{C}$ for $16 \mathrm{~h}$ to a constant weight, and then naturally cooled down to the ambient temperature and weighed. After that the fragments were subjected to heating at $1000^{\circ} \mathrm{C}$ for $20 \mathrm{~min}$, and then cooled down and weighed. Each test was repeated three times to ensure accuracy. The data recorded were subsequently used to calculate the chemically bound water content in the paste samples.

\subsection{XRD Analysis of Hydration Products of RHA Incorporated Cement Paste}

To investigate the effect of RHA on the hydration products of cement, the XRD analysis of cement pastes without and with water-leaching and acid-leaching-pretreated RHA were determined at the age of 7 days. The XRD scanning were performed at two theta between $10^{\circ}$ to $60^{\circ}$.

\section{Results and Discussion}

\subsection{Chemical Compositions and Physical Properties of RHA}

Chemical compositions and physical properties of RHAs without and with pretreatment are summarized in Tables 1 and 2, respectively. It is seen that silica oxide forms the main component $(89-96 \%)$ of RHAs with trace elements in the form of composite oxides $\mathrm{K}_{2} \mathrm{O}, \mathrm{Na}_{2} \mathrm{O}, \mathrm{CaO}, \mathrm{MgO}, \mathrm{Fe}_{2} \mathrm{O}_{3}$, and $\mathrm{Al}_{2} \mathrm{O}_{3}$. In the case of unpretreated RHA, $89.6 \%$ of silica was produced by calcining $\mathrm{RH}$ at $600{ }^{\circ} \mathrm{C}$ for $2 \mathrm{~h}$. Potassium (K) was detected to account for the highest concentration (2.53\%) among the metallic trace elements. With the increase in calcination temperature and duration, silica content and undesirable carbon residue (represented by LOI) were slightly increased. The specific surface area tends to decrease with the increase of calcination temperature and duration, contributing to the particle agglomeration. It is apparent that the capacity of controlled calcination condition for improving the silica purity and chemical reactivity of silica is rather limited.

The leaching pretreatment process results in significant changes in trace element concentrations in RHA. In the case of acid-leaching pretreatment, $\mathrm{HCl}$ exerts superior performance in removing metallic impurities to the other leaching agents. The RHA yielded by $1 \mathrm{~N} \mathrm{HCl}$ leaching pretreatment and calcination at $600{ }^{\circ} \mathrm{C}$ for $2 \mathrm{~h}$ possesses the highest silica content $(96.41 \%)$ and surface area $\left(248.21 \mathrm{~m}^{2} / \mathrm{g}\right)$. The trace elements are reduced to a very low level, especially in the case of potassium, which is reduced to $0.06 \%$. $\mathrm{HNO}_{3}$ and $\mathrm{H}_{2} \mathrm{SO}_{4}$ as leaching agents also have excellent performance in washing off alkali metals and improving the surface area, as well as reducing the carbon residue content of RHA.

In the case of boiling-water-leaching pretreatment, the RH pretreated by boiling water leaching for $2.5 \mathrm{~h}$ and burning out at $600{ }^{\circ} \mathrm{C}$ for $2 \mathrm{~h}$ yields RHA with a silica content of $94.03 \%$ and a surface area of $130.82 \mathrm{~m}^{2} / \mathrm{g}$. However, extending the water-leaching duration to $10 \mathrm{~h}$ does not seem like a responsible way to increase the concentration and surface area of silica. Thus, a water-leaching duration of $2.5 \mathrm{~h}$ is sufficient for pretreating RH to extract pure silica. It is worth noting that, although the boiling water-leaching pretreatment is inferior in extracting a high content of silica and rinsing off metallic impurities in RH during the acid-leaching pretreatment, the boiling water-leaching pretreatment method is more eco-friendly and economical. 
The weight loss data obtained from thermogravimetric studies are presented in Table 1. It is clearly seen that the residual organics or undesirable carbon of RHA are gotten rid of with greater ease from the acid-leaching- or water-leaching-pretreated RH upon heating in comparison to that of the unpretreated RHA.

Table 1. Chemical composition of RHAs.

\begin{tabular}{ccccccccc}
\hline RHA Samples & $\mathbf{S i O}_{\mathbf{2}}(\mathbf{\%})$ & $\mathbf{K}_{\mathbf{2}} \mathbf{O}(\mathbf{\%})$ & $\mathbf{N a}_{\mathbf{2}} \mathbf{O}(\%)$ & $\mathbf{C a O}(\%)$ & $\mathbf{M g O}(\%)$ & $\mathbf{A l}_{\mathbf{2}} \mathbf{O}_{\mathbf{3}}(\%)$ & $\mathrm{Fe}_{\mathbf{2}} \mathbf{O}_{\mathbf{3}}(\%)$ & $\mathbf{L O I}(\%)$ \\
\hline RHA600-2 & 89.61 & 2.53 & 0.16 & 1.52 & 0.56 & 0.36 & 0.90 & 3.53 \\
RHA600-8 & 90.42 & 2.48 & 0.14 & 1.57 & 0.59 & 0.39 & 0.88 & 3.74 \\
RHA900-2 & 91.76 & 2.13 & 0.11 & 1.33 & 0.62 & 0.33 & 0.79 & 4.61 \\
RHA1200-0.5 & 92.23 & 1.92 & 0.09 & 1.21 & 0.71 & 0.28 & 0.37 & 4.92 \\
1Cl-RHA600-2 & 96.41 & 0.06 & 0.05 & 0.07 & 0.24 & 0.19 & 0.28 & 1.80 \\
1S-RHA600-2 & 95.52 & 0.07 & 0.07 & 0.64 & 0.22 & 0.21 & 0.32 & 2.24 \\
1N-RHA600-2 & 95.81 & 0.06 & 0.06 & 0.59 & 0.22 & 0.18 & 0.29 & 2.11 \\
2.5W-RHA600-2 & 94.03 & 0.26 & 0.12 & 0.95 & 0.32 & 0.23 & 0.33 & 3.32 \\
2.5W-RHA900-2 & 94.42 & 0.24 & 0.09 & 0.99 & 0.41 & 0.22 & 0.31 & 2.04 \\
5W-RHA900-2 & 94.80 & 0.22 & 0.10 & 0.95 & 0.29 & 0.21 & 0.29 & 2.96 \\
10W-RHA900-2 & 94.92 & 0.21 & 0.11 & 0.92 & 0.29 & 0.19 & 0.28 & 2.90 \\
\hline
\end{tabular}

Note: LOI represents the loss of ignition.

The average particle size, BET surface area, pore volume, and pore diameter of RHA samples are given in Table 2. It is seen that leaching pretreatment significantly affects the surface area as well as the pore volume of RHA silica. The average pore diameter of acid-leached RHA, water-leached RHA, and unpretreated RHA is around 6, 6 and $32 \mathrm{~nm}$, respectively, indicating that the RHAs produced are mainly mesoporous. The pore volume of the acid-leached RHA and the water-leached RHA are higher than that of the unpretreated one. It is noteworthy that either the acid-leaching pretreatment or the water-leaching pretreatment can markedly increase the surface area and the pore volume, as well as reduce the pore diameter of RHA. This is mainly attributed to the hydrolysis of lignin and cellulose into smaller compounds and the dissolution of alkali metals after leaching pretreatment, which promote the volatilization of fixed carbon in RHA with greater ease during combustion. Moreover, the removal of the organic carbohydrates causes the inside pores in RHA to open and hence leads to a more loose and highly porous structure of RHA.

Table 2. Particle size, BET surface area, and conductivity of RHAs.

\begin{tabular}{|c|c|c|c|c|c|}
\hline RHA Samples & $\begin{array}{c}\text { Average } \\
\text { Particle Size } \\
(\mu \mathrm{m})\end{array}$ & $\begin{array}{l}\text { BET Surface } \\
\text { Area }\left(\mathrm{m}^{2} / \mathrm{g}\right)\end{array}$ & $\begin{array}{l}\text { Total Pore } \\
\text { Volume } \\
\left(\mathrm{cm}^{3} / \mathrm{g}\right)\end{array}$ & $\begin{array}{l}\text { Average Pore } \\
\text { Diameter (nm) }\end{array}$ & $\begin{array}{c}\text { Conductivity } \\
\text { Change } \\
(\mathrm{ms} / \mathrm{cm})\end{array}$ \\
\hline RHA600-2 & 5.47 & 74.88 & 0.082997 & 32.78 & 0.38 \\
\hline RHA600-8 & 6.21 & 68.83 & 0.072315 & 33.19 & 0.42 \\
\hline RHA900-2 & 6.47 & 10.59 & 0.053497 & 35.14 & 0.11 \\
\hline RHA1200-0.5 & 6.96 & 10.02 & 0.042749 & 38.17 & 0.00 \\
\hline 1Cl-RHA600-2 & 5.02 & 248.21 & 0.368958 & 5.15 & 6.09 \\
\hline 1Cl-RHA900-2 & 5.63 & 250.32 & 0.312846 & 6.07 & 6.11 \\
\hline 1Cl-RHA1200-0.5 & 6.21 & 200.02 & 0.287963 & 7.70 & 0.22 \\
\hline 1S-RHA600-2 & 5.20 & 232.97 & 0.324875 & 5.38 & 5.73 \\
\hline 1N-RHA600-2 & 5.14 & 241.76 & 0.357947 & 5.23 & 5.91 \\
\hline 2.5W-RHA600-2 & 5.34 & 130.82 & 0.257617 & 6.45 & 4.42 \\
\hline 2.5W-RHA900-2 & 6.02 & 120.85 & 0.184237 & 7.02 & 4.64 \\
\hline 5W-RHA900-2 & 5.88 & 133.78 & 0.274633 & 6.88 & 4.75 \\
\hline 10W-RHA900-2 & 5.42 & 137.96 & 0.302141 & 6.64 & 4.87 \\
\hline
\end{tabular}

The $\mathrm{N}_{2}$ adsorption-desorption isotherms and pore size distribution curves of the RHA samples are shown in Figure 1, respectively. It is seen that the adsorption is not limited to high values of P/P0 above 0.95 . In addition, the isotherms present a vertical asymptotic profile at high values of $\mathrm{P} / \mathrm{P} 0$, which is characteristic of a mesoporous structure with non-uniform sized particles. 
It is seen from Figure 1a that the unpretreated RHA presented the type I hysteresis loop [30] according to de Boer's classification of hysteresis loops, suggesting an intergranular pore structure formed by the spherical granules compactly accumulating together. As shown in Figure $1 b, c$, both the boiling water-pretreated RHA and the acid-pretreated RHA present type III hysteresis loops, indicating a bottle-shaped pore structure. The absorption and desorption of type III isotherms are more steep, suggesting that the porosity of the pretreated RHA is higher than that of the unpretreated one.

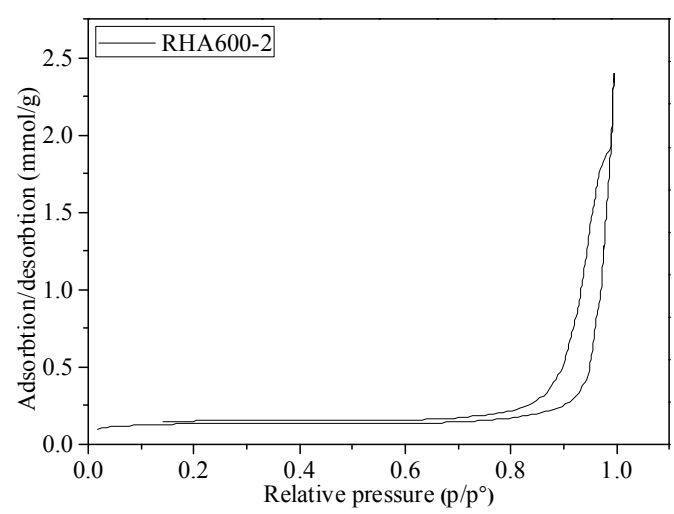

(a)

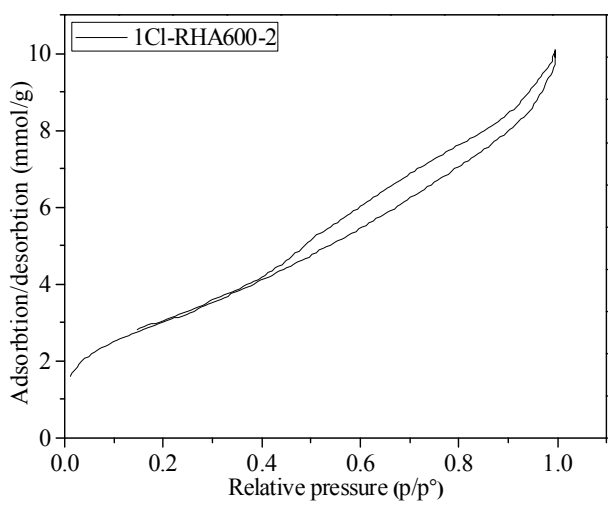

(b)

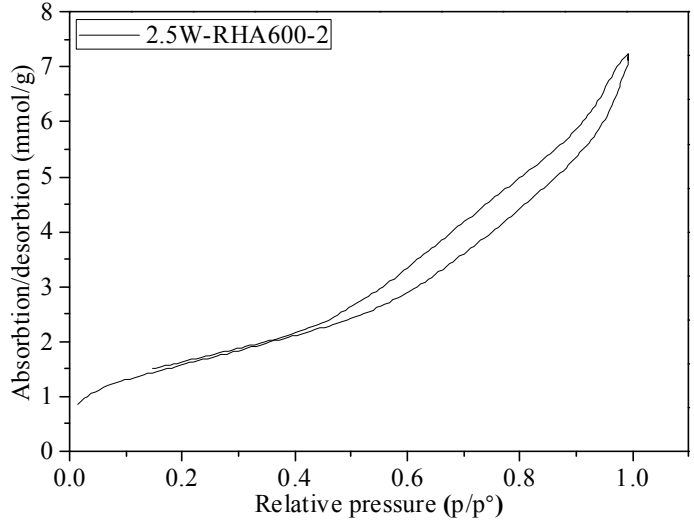

(c)

Figure 1. Nitrogen adsorption-desorption isotherm for (a) untreated RHA; (b) acid-treated RHA and (c) water-treated RHA.

Figure 2 gives the information on the BJH pore volume and diameter of RHAs. It is seen from Figure $2 \mathrm{a}$ that the unpretreated RHA has a mean pore diameter of $32.7804 \mathrm{~nm}$, indicating that it is between mesoporous and macroporous. Its pore volume is $0.082997 \mathrm{~cm}^{3} / \mathrm{g}$, suggesting a low quantity of pores. In contrast, the acid-leaching and water-leaching pretreatment lead to a reduction of RHA pore diameter to 6.4479 and $5.1521 \mathrm{~nm}$, and an increase of pore volume to 0.257617 and $0.368958 \mathrm{~cm}^{3} / \mathrm{g}$, respectively. It is evident that leaching pretreatment improves the internal porosity of RHA. 


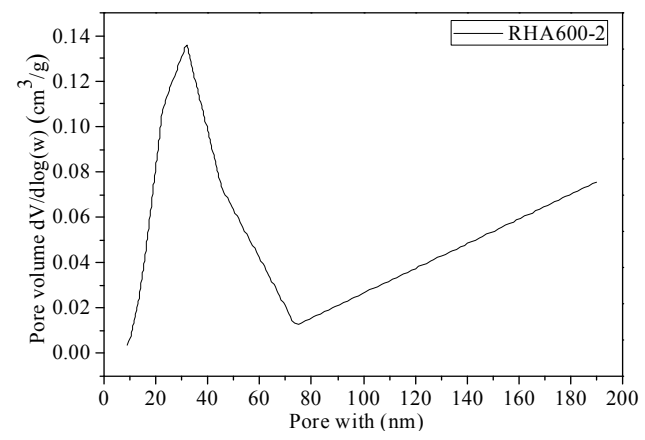

(a)

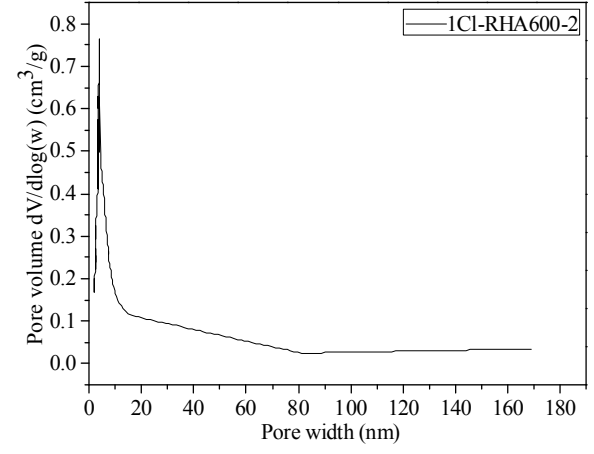

(b)

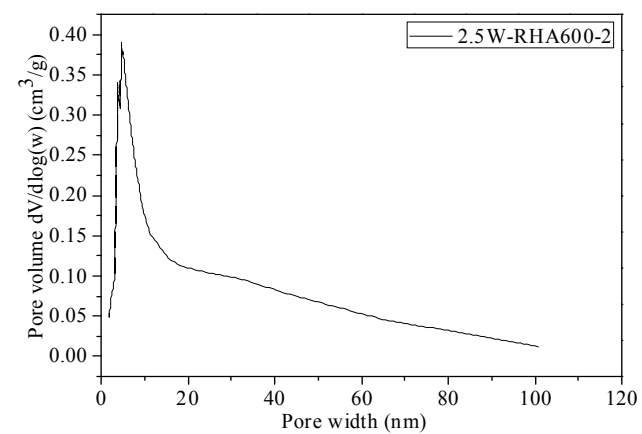

(c)

Figure 2. Pore size distribution calculated via BJH algorithm of (a) untreated RHA; (b) acid-treated RHA and (c) water-treated RHA.

\subsection{Conductivity Change Test of RHA}

The conductivity change testing results are listed in Table 2 . The conductivity change value is an indication of the pozzolanic reactivity of the testing powder. The greater the change value in conductivity of the testing solution, the higher the chemical reactivity of RHA silica. The conductivity change value of RHA silica shows both leaching pretreatment- and pyrolysis condition- (temperature and duration) dependent behavior. In the case of unpretreated ash RHA600-2, the conductivity change value is 0.38 . In the case of acid-leaching-pretreated RHA samples, the conductivity change value of 1Cl-RHA600-2, 1N-RHA600-2 and 1S-RHA600-2 is 6.09, 5.91, and 5.73, which is $1502.6 \%$, $1407.9 \%$, and $1243.2 \%$ higher, respectively, than that of the unpretreated ash RHA600-2. In the case of water-leaching-pretreated RHA samples, the conductivity change value of 2.5W-RHA600-2 and 2.5W-RHA900-2 is 4.42 and 4.64 , which is $1063.2 \%$ and $1121.1 \%$ higher, respectively, than that of RHA600-2. It is apparent that with the assistance of an acid- or water-leaching process, the metallic concentration in RH is significantly reduced, while the chemical reactivity of the yielded RHA is distinctly increased as compared to the unpretreated one. In addition, it is noteworthy that prolonging the duration of water leaching does not lead to an obvious improvement in the conductivity change value of the testing solution. In other words, excessive water-leaching pretreatment time is not related to a significant increase in the pozzolanic reactivity of RHA. Thus, a duration of $2.5 \mathrm{~h}$ for boiling water leaching is reasonable and economical.

\subsection{FTIR Analysis of RH and RHA}

The FTIR spectra of the unpretreated, HCl-leaching-pretreated, and water-leaching-pretreated RHs are shown in Figure 3. The broad band observed around $3420 \mathrm{~cm}^{-1}$ is attributed to the stretching vibration of $\mathrm{C}-\mathrm{H}$ and $\mathrm{OH}$ groups, indicating the cellulose structure and water absorption (hydroxyl groups bound to the cellulose structure) in RH [31,32]. The band at $2929 \mathrm{~cm}^{-1}$ represents the stretching and / or vibration of the $\mathrm{C}-\mathrm{H}$ group, attributed to the aliphatic-saturated compounds in the cellulose [33]. A slight shoulder at $1740 \mathrm{~cm}^{-1}$ is referent to the stretching vibration of the $\mathrm{C}=\mathrm{O}$ bond in hemicellulose 
or carboxylic acid groups in the ferulic and $p$-coumaric components of the lignin [31,34]. These organic groups suggest that the cellulose and lignin are not rinsed off from $\mathrm{RH}$ by the acid-leaching or water-leaching pretreatment. The characteristic absorption peaks of $\mathrm{SiO}_{2}$ appear at $480 \mathrm{~cm}^{-1}$ (bending vibration of O-Si-O), $800-820 \mathrm{~cm}^{-1}$ (stretching vibration of Si-O-Si or Si-C), and $1110-1130 \mathrm{~cm}^{-1}$ (asymmetric stretching vibration of Si-O-Si) $[35,36]$.

In general, the FTIR spectra of RHs without and with pretreatment showed similar trend curves, suggesting that the leaching pretreatment does not change the functional group structure of $\mathrm{SiO}_{2}$ and the main organic matter (cellulose and lignin) in $\mathrm{RH}$. However, the characteristic peaks of $\mathrm{SiO}_{2}$ $\left(480 \mathrm{~cm}^{-1}, 800-820 \mathrm{~cm}^{-1}\right.$, and $\left.1110-1130 \mathrm{~cm}^{-1}\right), \mathrm{C}=\mathrm{O}$ group $\left(1740 \mathrm{~cm}^{-1}\right)$, and C-H group $\left(2929 \mathrm{~cm}^{-1}\right)$ of $\mathrm{RH}$ samples by water- or acid-leaching pretreatment are more obvious than those of the unpretreated one. This is due to the fact that leaching pretreatment removes most of the metallic impurities, so that the concentration of $\mathrm{SiO}_{2}$ and carbon-containing compounds become more apparent, and the enhancing effect is more pronounced in the case of the acid-pretreated $\mathrm{RH}$.

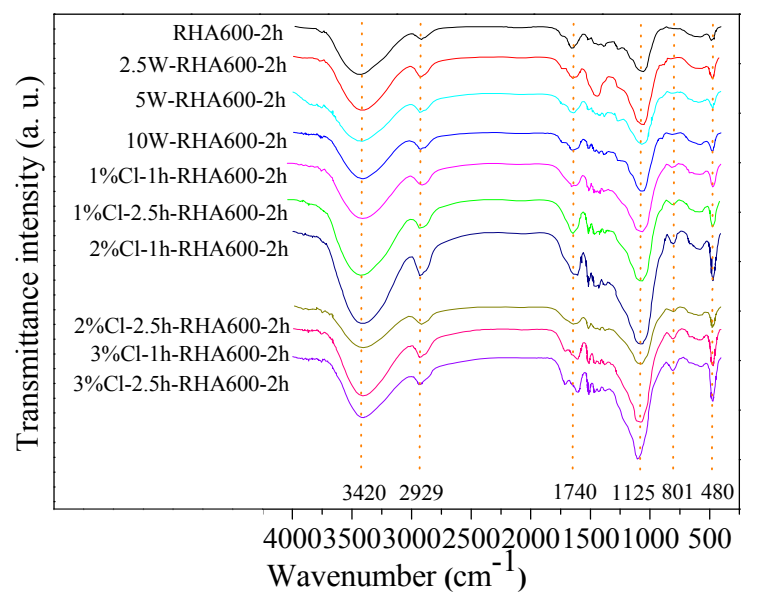

Figure 3. FTIR spectra of RH with and without various pretreatments.

The FTIR spectra of RHAs are illustrated in Figure 4. It is seen that, after pyrolysis, the C-H bond $\left(2929 \mathrm{~cm}^{-1}\right)$ and the $\mathrm{C}=\mathrm{O}$ bond $\left(1740 \mathrm{~cm}^{-1}\right)$ referent to the functional groups of cellulose and lignin disappear for all the ash samples, suggesting that most of the organic compounds are burnt out. The intensity of $\mathrm{SiO}_{2}$ characteristic peaks at $480,800-820$, and $1110-1130 \mathrm{~cm}^{-1}$ of RHAs follows the ascending order of the untreated RHA, the water-leaching-pretreated RHA, and the acid-leaching-pretreated RHA, suggesting that the reactivity of the leaching-pretreated RHA is higher than that of the unpretreated one.

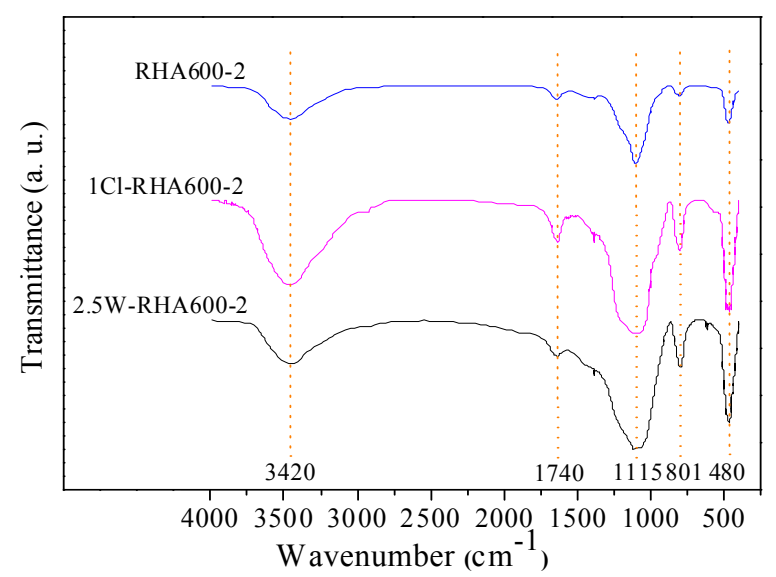

Figure 4. FTIR spectra of RHA with and without various pretreatments. 


\subsection{SEM Morphology of RHs}

The SEM morphologies of the outer surface, inside surface, and interlayer of the water-leaching-pretreated RH are presented in Figure 5. Figure 5a presents the outer surface of the water-pretreated RH. The outer surface is uneven and highly roughened. Many bulges are neatly arranged with a crochet sprout between. From Figure $5 b$, it is seen that the inner surface of the RH is smooth and dense. Figure $5 \mathrm{c}$ is a cross-sectional view of the RH interlayer. It is seen that the porous inside layer is a plate-like structure constituted of a multilayer mesoporous structure. It is apparent that the water-leaching pretreatment does not significantly change the surface morphology or inner skeleton structure of $\mathrm{RH}$.

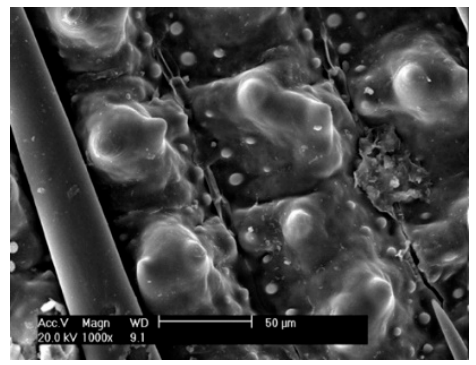

(a)

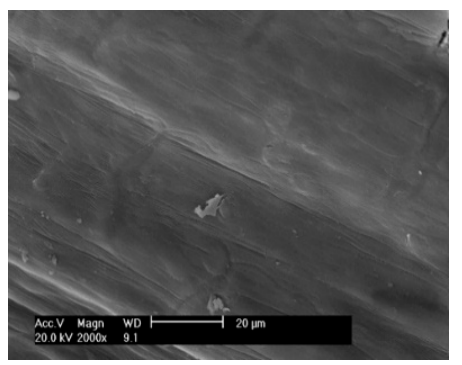

(b)

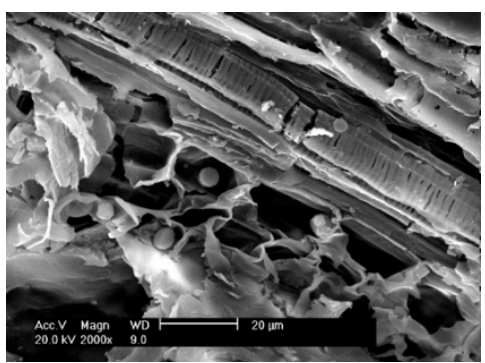

(c)

Figure 5. SEM morphologies of (a) outside surface; (b) inside surface and (c) interlayer of the water-leached RH.

The morphologies of the outer surface, inside surface, and cross section morphology of the $\mathrm{HCl}$ leaching pretreated RH are presented in Figure 6a-c respectively. It is seen that, after acid leaching, the outer surfaces, smooth inside surface, and porous interlayer of RH were significantly corroded as compared to the corresponding part of the water-leaching-pretreated one shown in Figure 5. These morphological changes are presumably due to the hydrolysis of some organic components by acid.

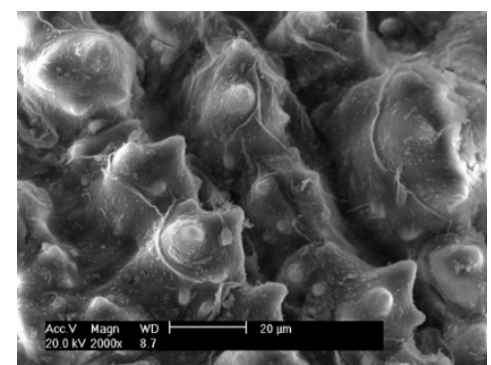

(a)

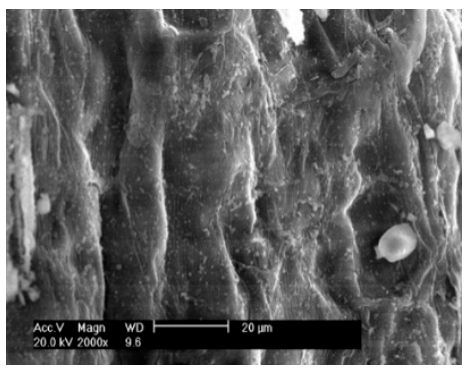

(b)

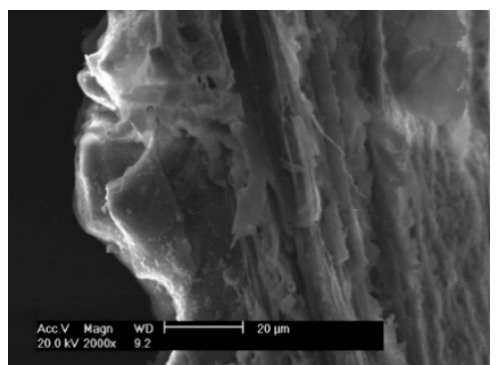

(c)

Figure 6. SEM morphologies of (a) outside surface, (b) inside surface, and (c) interlayer of the acid-leached RH.

\subsection{XRD Analysis of RHA}

XRD spectra of the unpretreated RHA, the water-leaching-pretreated RHA, and the acid-leaching-pretreated RHA with various calcination temperatures and durations are shown in Figure 7 . The XRD patterns of unpretreated RHA obtained by calcining at various temperatures are shown in Figure 7a. It is seen that broad diffused peaks with maximum intensity at $2 \theta=22.5^{\circ}$ are observed at RHA600-2, indicating the amorphous nature of silica. At $700{ }^{\circ} \mathrm{C}$ the presence of quartz $\left(2 \theta=26.7^{\circ}\right)$ is observed. As the temperature increased to $900^{\circ} \mathrm{C}$, cristobalite $\left(2 \theta=22.5^{\circ}\right)$ and tridymite $\left(2 \theta=26^{\circ}\right)$ were also detected, as reflected by the peak intensities. These phenomena demonstrate the thermal instability of amorphous silica of unpretreated $\mathrm{RH}$, which has been extensively shown in previous research works $[5,37]$. The phase transformation of RHA silica from amorphous to crystalline 
is very sensitive to pyrolysis temperatures above $700{ }^{\circ} \mathrm{C}$. Hence, the crystallization sensitivity nature of RHA silica challenges the mass production of highly reactive silica based on existing industrial calcination equipment and techniques.

It has been reported elsewhere [38] that the presence of alkali metal salts results in a marked decrease in the crystallization temperature of the eutectic silica in $\mathrm{RH}$. The calcination-temperature-dependent nature of silica is remarkably weakened by leaching treatment, as confirmed in Figure $7 \mathrm{~b}$. It is evident that acid-leaching-pretreated RHA silica shows completely amorphous structures upon combustion at $900{ }^{\circ} \mathrm{C}$ for $6 \mathrm{~h}$. In addition, water-leaching-pretreated RHA silica presents similar mineralogical features at this thermal station. This is because of the removal of alkali metals, which preferably react with RHA silica to form eutectic composite with a low crystalline temperature. However, as the calcination duration extends to $7 \mathrm{~h}$, the incipient cristobalite formation becomes apparent in the XRD patterns of the water-leaching-pretreated RHA silica powders. When pyrolysis takes place at $1200{ }^{\circ} \mathrm{C}$ for $0.5 \mathrm{~h}$, the crystalline impurities cristobalite and quartz predominate. In the case of acid-leaching-pretreated RHA silica at this pyrolysis stage, tenuous peaks of cristobalite and tridymite gradually began to be visible, suggesting that crystalline silica formation starts to occur. It is seen that the ceiling capability for water-leaching pretreatment is to keep silica amorphous at $900{ }^{\circ} \mathrm{C}$ for $7 \mathrm{~h}$. At $1200^{\circ} \mathrm{C}$, as shown in Figure $7 \mathrm{~d}$, small elevations corresponding to patterns of cristobalite and quartz arise in the acid-leached silica samples, i.e., acid-leaching pretreatment raises the crystalline transformation temperature of silica up to $1200{ }^{\circ} \mathrm{C}$. In the case of water-leaching-pretreated RHA, cristobalite and quartz are formed to a large extent, along with the tenuous appearance of tridymite. It is apparent that the acid-leaching pretreatment has superior performance to the water-leaching pretreatment in reducing the crystallization sensitivity of RHA silica. However, the water-leaching treatment can use industrial cooling water as the leaching agent, hence reducing the investment in process technology and sophisticated equipment in comparison to acid-leaching treatment.
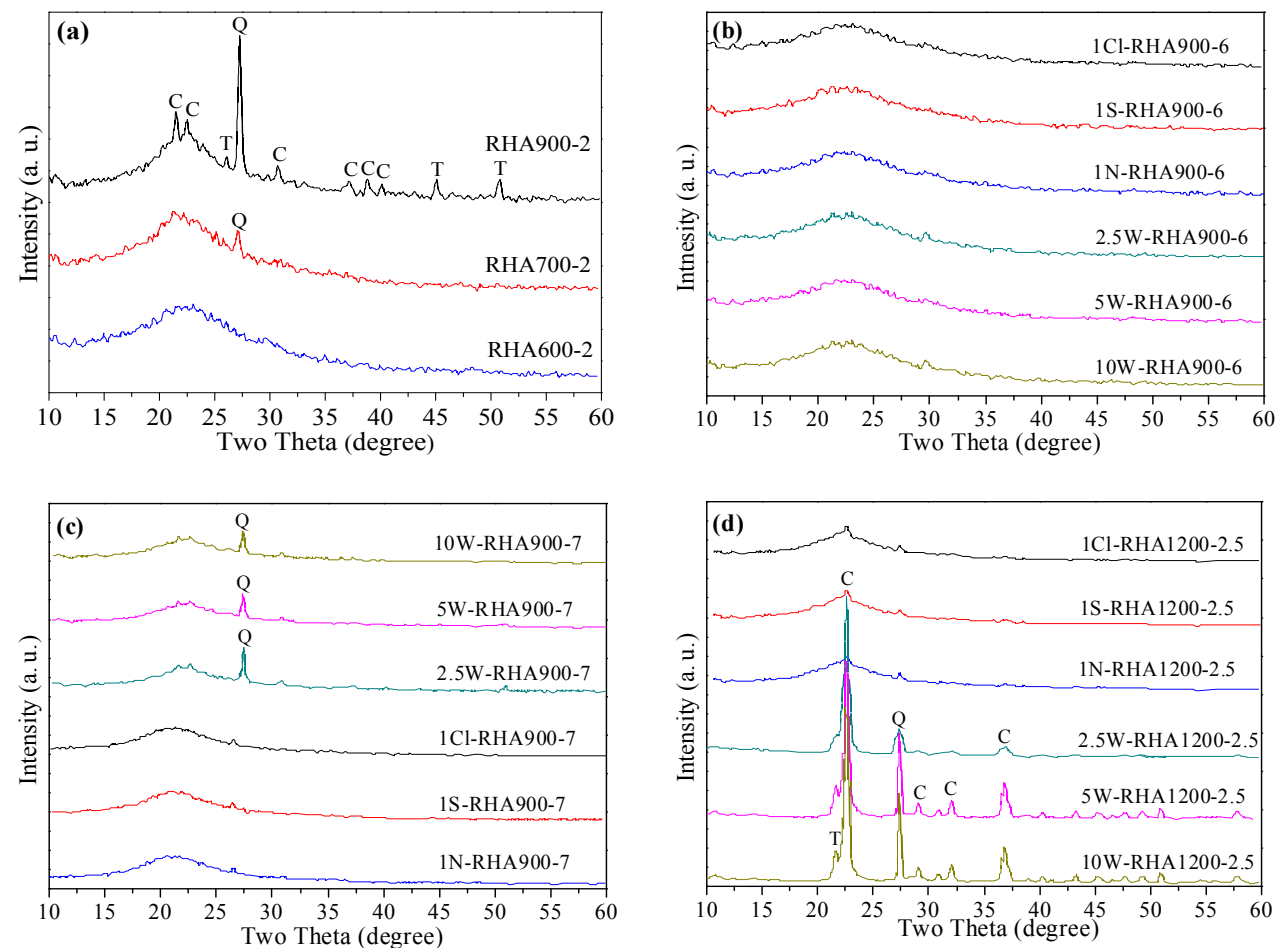

Figure 7. XRD spectra of RHAs obtained from: (a) unpretreated RHs burnt out at 600,700 , and $900{ }^{\circ} \mathrm{C}$ for $2 \mathrm{~h}$; (b) various leaching-pretreated RHs burnt out at $900{ }^{\circ} \mathrm{C}$ for $6 \mathrm{~h}$; (c) various leaching-pretreated RHs burnt out at $900{ }^{\circ} \mathrm{C}$ for $7 \mathrm{~h}$; (d) various leaching-pretreated RHs burnt out at $1200{ }^{\circ} \mathrm{C}$ for $2.5 \mathrm{~h}$. ( $\mathrm{C}=$ cristobalite; $\mathrm{Q}=$ quartz; $\mathrm{T}=$ tridymite). 


\subsection{Influence of Alkali Metals on Crystallization in RHA Silica}

To identify the influences of metallic impurity and content on thermal stability of RHA silica, mixtures of $1 \mathrm{~N} \mathrm{HCl}$-purified $\mathrm{RH}$ incorporated $2 \mathrm{wt} \%$ various alkali metallic trace elements in the form of chlorine salts are subjected to burning out at $600{ }^{\circ} \mathrm{C}$ for $2 \mathrm{~h}$. The XRD spectra of the ash mixtures are plotted in Figure 8a. It is seen that a sharp intensity peak at $2 \theta=22.5^{\circ}$ corresponding to cristobalite is noticed in the XRD pattern. Similarly, the incorporation of $\mathrm{NaCl}_{2}, \mathrm{MgCl}_{2}$, and $\mathrm{CaCl}_{2}$ into silica promotes formation of the crystals cristobalite and quartz in the resulting blends. In the case of $\mathrm{NaCl}_{2} \& 1 \mathrm{Cl}-\mathrm{RH}$ ash blends, an incipient peak referent to the tridymite at $2 \theta=23^{\circ}$ is observed, suggesting that $\mathrm{Mg}$ promotes tridymite formation. However, silica blend with the incorporation of $\mathrm{AlCl}_{3}$ and $\mathrm{FeCl}_{2}$ shows no obvious $\mathrm{SiO}_{2}$ crystallization, indicating that the trace elements $\mathrm{Al}$ and $\mathrm{Fe}$ rarely contribute to promoting the crystallization of RHA silica.
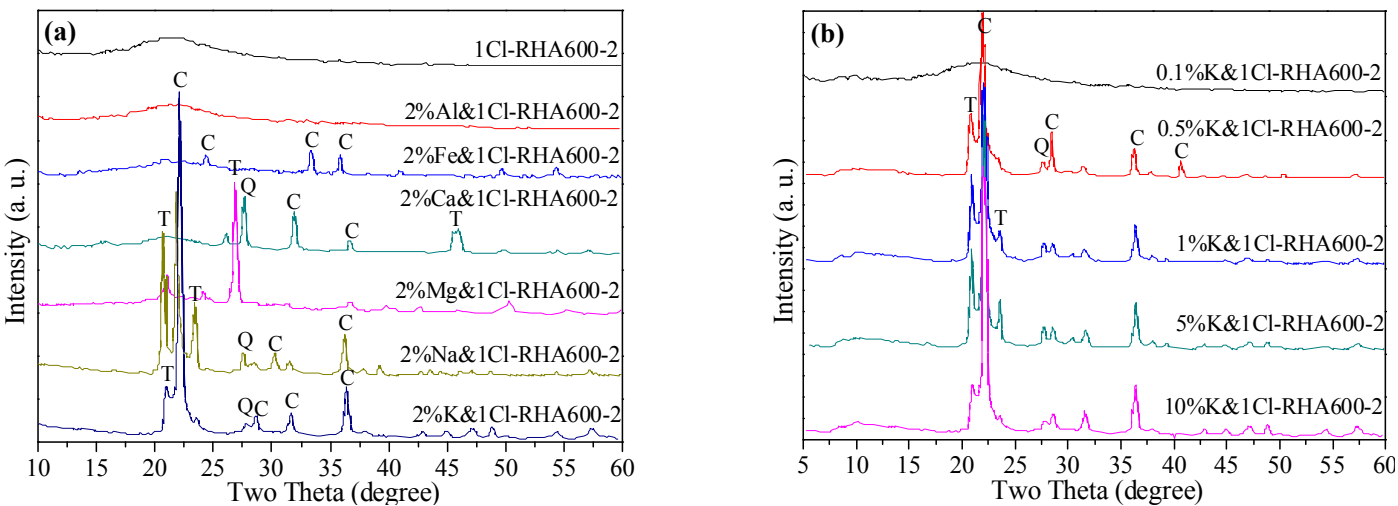

Figure 8. XRD spectra of (a) the mixture of HCl-pretreated $\mathrm{RH}$ and chlorine salts after burning out at $600{ }^{\circ} \mathrm{C}$ for $2 \mathrm{~h}$; (b) the mixture of $\mathrm{HCl}$-pretreated RHA silica various dosage of $\mathrm{KCl}$ after burning out at $600{ }^{\circ} \mathrm{C}$ for $2 \mathrm{~h}$. ( $\mathrm{C}=$ cristoballite; $\mathrm{Q}=$ quartz; $\mathrm{T}=$ tridymite $)$.

Combined with the XRF chemical composition results, $\mathrm{K}$ is detected as the most abundant trace element in RHA, and hence it is the major contributor leading to the reduction of the crystallization temperature of the eutectic silica system. This finding is in line with the report of Krishnarao et al. [28]. It is also interesting to note the effect of $\mathrm{K}$ content on the crystallization behavior of RHA silica. The XRD spectra of the $1 \mathrm{~N} \mathrm{HCl}$-purified RH-incorporated mixtures with various addition ratios of $\mathrm{K}$ are given in Figure $8 \mathrm{~b}$. It is seen that a $0.1 \%$ addition of $\mathrm{K}$ has no impact on the crystallization of the silica blend. With the incorporation ratio of $\mathrm{K}$ increasing to $0.5 \%$ and above, the detraction crystalline peak corresponding to cristobalite becomes intensive and sharp. Thus, it is inferred that $\mathrm{K}$ exerts its function in accelerating the crystallization of RHA silica when its concentration in RHA is beyond $0.5 \%$.

\subsection{Compressive Strength of RHA Incorporated Cement Paste}

To investigate the pozzolanic reactivity of the RHA silica, a compressive strength test of the blended cement paste was carried out. The compressive strength results of paste specimens at the age of three, seven, and 28 days are shown in Figure 9. P0 is the control paste. PR represents the paste with $10 \%$ cement replaced by the RHA obtained by burning RH at $600{ }^{\circ} \mathrm{C}$ for $2 \mathrm{~h}$. P2.5WR, P5WR, and P10WR denote pastes with 10\% cement replaced by the RHA obtained from water-leaching pretreatment on $\mathrm{RH}$ for $2.5,5$, and $10 \mathrm{~h}$, respectively, and then burning out at $600{ }^{\circ} \mathrm{C}$ for $2 \mathrm{~h}$. PClR stands for the paste with $10 \%$ cement replaced by the RHA obtained from $1 \mathrm{~N}$ hydrochloric on RH for $1 \mathrm{~h}$ and then burning out at $600{ }^{\circ} \mathrm{C}$ for $2 \mathrm{~h}$.

It is seen that the compressive strength of paste undergoes a significant improvement when $10 \%$ of RHA is incorporated. The compressive strength of paste with unpretreated RHA is $20.2 \%$ higher than that of the control paste. The enhancing effect of RHA is improved by leaching pretreatment on 
$\mathrm{RH}$ prior to calcination. This can be attributed to the high silica content and high specific surface area of the leaching-pretreated RHA silica. The highest compressive strength appears in the paste with incorporation of acid-leaching-pretreated RHA (67.4 MPa), and the value is $48.1 \%$ higher than that of the control paste. In the case of the water-leaching-pretreated, RHA-incorporated cement paste, the RH with water-leaching pretreatment for $2.5 \mathrm{~h}$ yields the resulting RHA-blended paste having a compressive strength of $64.8 \mathrm{MPa}$, and this value is $42.4 \%$ higher than that of the control paste. Prolonging the water-leaching duration to $10 \mathrm{~h}$, the strength value of the resulting ash-incorporated cement paste is increased to $65.6 \mathrm{Mpa}$. It is apparent that extending the water-leaching duration does not lead to obvious improvement in the pozzolanic reactivity of RHA. Thus, $2.5 \mathrm{~h}$ is an acceptable duration for water-leaching pretreatment on $\mathrm{RH}$ to yield a highly reactive pozzolana. It is worth noting that the water-leaching-pretreated RHA has better performance at improving the compressive strength of cement paste as compared to undispersed silica fume, as reported by Ji et al. [39], and presents comparable pozzolanic reactivity to dispersed silica fume and metakaolin, as per [40]. The enhancing effect of RHA on the compactness of the cement body is attributed to the silicate tetrahedron of RHA participating in the composition of hydrated calcium silicate (C-S-H) to prolong the chains of C-S-H, and soluble silicate-oxide chains of RHA also react with the free $\mathrm{Ca}(\mathrm{OH})_{2}$ released from the cement hydration to form more C-S-H phase in the cement matrix [41].

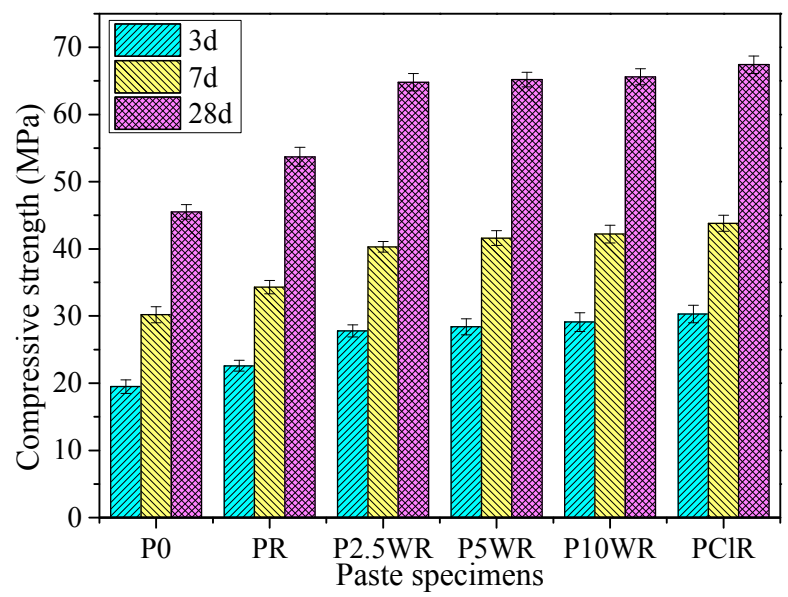

Figure 9. Compressive strength as a function of age for RHA cement paste.

\subsection{Chemically Bound Water Content of RHA Incorporated Cement Paste}

To investigate the effect of the RHA silica on the hydration degree of cement matrix, the chemically bound water of the paste fragments of the above compressive strength test was calculated.

The water in the hardened cement paste is divided into evaporated water (free water) and non-evaporated water (chemically bound water). A study [42] has revealed that the volume of evaporating water can be used as a measure of the pore volume in the cement paste, while the amount of non-evaporating water refers to the amount of hydration products. Therefore, the amount of chemically bound water measured at different ages can be used as a representative value of the degree of hydration of cement paste. The unit mass of chemical combined water was calculated as in the following equation:

$$
\mathrm{X} 1 \text { = (M1 - M2)/M2 - Xad.c/(1 - Xad.c), }
$$

where $\mathrm{X} 1$ is the chemical combined water content per unit mass of cementitious material, M1 is the quality of the paste sample after drying at $105{ }^{\circ} \mathrm{C}$, and $\mathrm{M} 2$ is the quality of the sample after drying at $1000^{\circ} \mathrm{C}$. Xad.c refers to Equation (2):

$$
\text { Xad.c }=\text { XadXad.1 }+ \text { XcXc.1, }
$$


where $X_{a d}$ and $X_{c}$ are the mass fraction of the admixture and cement, respectively; Xad.1 and $X_{c} .1$ are the loss on ignition of the admixture and cement, respectively.

The amount of chemically bound water of the cement paste at the early age is expressed in terms of unit mass of cement and denoted as X2, as per Equation (3):

$$
\mathrm{X} 2=\mathrm{X} 1 /(1-\mathrm{Xad})
$$

To quantitatively characterize the effect of admixture on cement hydration, a hydration influence factor $\mathrm{F}$ of the admixture is introduced and calculated as F = equivalent bound water (X2)/combined water of the pure cement at the same age. If $\mathrm{F}$ is more than 1 , the admixture promotes the hydration of the cement. The larger the value, the more obvious the promotion effect; if $F$ is less than 1 , the admixture delays the hydration of the cement. The larger the value, the more obvious the delay effect.

The chemically bound water results of RHA incorporated cement paste specimens are shown in Table 3. It is seen that the chemically bound water in control paste was only $11.3 \%$ and $19.7 \%$ at the age of and 28 days, while addition of the RHA results in a remarkable increase in the content of chemically bound water in the resulting paste at each age. In the case of the paste with incorporation of the water-leaching-pretreated RHA, the chemically bound water of 28 days is improved to 29.3 to $30.2 \%$ depending on the leaching duration, and the variation is not very noticeable. The paste with hydrochloric acid pretreated RHA shows the chemically bound water content is $30.3 \%$, which is the highest value. These calculation results are in line with the conductivity and compressive strength results. It is also worth noting that the boiling-water-pretreated RHA silica has a comparable performance at improving the cement hydration with the acid-pretreated one.

Table 3. Chemical combined water and factors of RHA pastes.

\begin{tabular}{ccccc}
\hline \multirow{2}{*}{ Paste Samples } & \multicolumn{2}{c}{ 7 Days } & \multicolumn{2}{c}{ 28 Days } \\
\cline { 2 - 5 } & $\mathbf{X 1}$ & $\mathbf{F}$ & $\mathbf{X 1}$ & $\mathbf{F}$ \\
\hline Control & $11.3 \%$ & 1 & $19.7 \%$ & 1 \\
PR & $11.8 \%$ & 1.16 & $21.6 \%$ & 1.22 \\
P2.5WR & $18.0 \%$ & 1.77 & $29.3 \%$ & 1.65 \\
P5WR & $18.5 \%$ & 1.82 & $29.5 \%$ & 1.66 \\
P10WR & $18.7 \%$ & 1.84 & $30.2 \%$ & 1.70 \\
PCIR & $18.7 \%$ & 1.86 & $30.3 \%$ & 1.72 \\
\hline
\end{tabular}

\subsection{XRD Analysis of Hydration Products of RHA Incorporated Cement Paste}

To investigate the effect of RHA silica on the hydration products of cement, the XRD analysis of paste samples P0, PR, P2.5W, P10W and PCl were determined at the age of 7 days. The results are plotted in Figure 10. It is seen that the intensity of $\mathrm{Ca}(\mathrm{OH})_{2}$ diffraction peak in the control cement paste P0 is very sharp. The addition of RHA weakens the X-ray diffraction peak intensity of $\mathrm{Ca}(\mathrm{OH})_{2}$. The phenomenon is attributed to the fact that silica in $\mathrm{RHA}$ can react with the free $\mathrm{Ca}(\mathrm{OH})_{2}$ to form crystalline or semi-crystalline hydrated calcium silicate (CSH), improving the compactness of the hardened cement body. In addition, the intensity of $\mathrm{Ca}(\mathrm{OH})_{2}$ diffraction peak is in the ascending order of the paste $\mathrm{PCl}, \mathrm{P} 10 \mathrm{~W}, \mathrm{P} 2.5 \mathrm{~W}, \mathrm{PR}$, and P0, indicating the pozzolanic reactivity of RHA following the descending order of 1Cl-RHA600-2, 10W-RHA900-2, 2.5W-RHA900-2, and RHA600-2. These results are in line with the compressive strength test and chemically bound water content test results. 


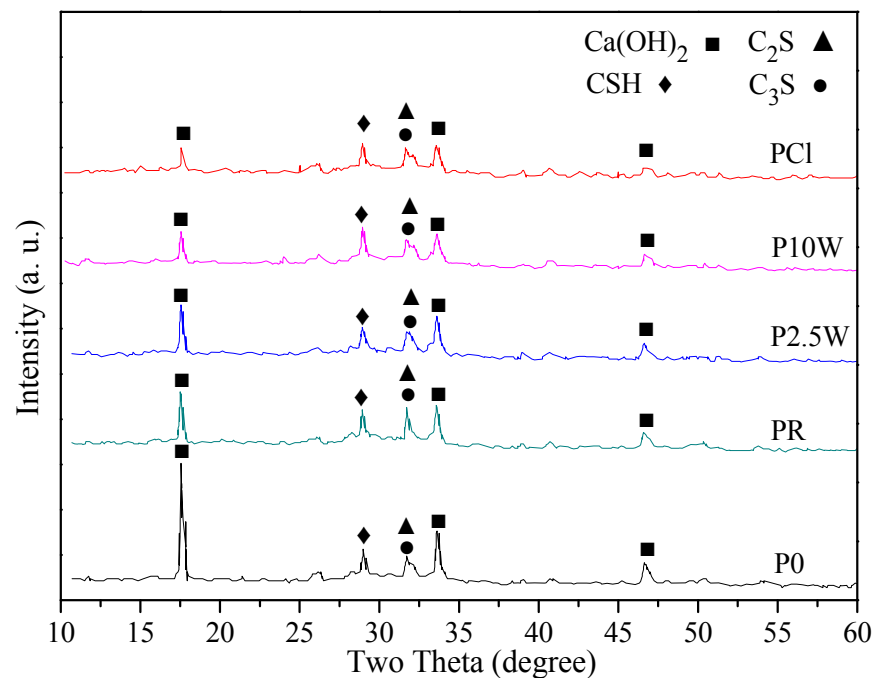

Figure 10. XRD patterns of RHA cement paste at the age of seven days.

\section{Conclusions}

After burning, RHs become RHA that normally contained $90 \%$ silica $\left(\mathrm{SiO}_{2}\right), 5-8 \%$ of alkali metal oxides, and some carbonaceous materials by mass. The reactive amorphous silica is extracted from RH via burning out of organic cellulose and lignin under controlled calcination at $600{ }^{\circ} \mathrm{C}$ for $2 \mathrm{~h}$. Raising the calcination temperature or extending the calcination duration can increase the silica concentration but lead to accelerated formation of crystalline compounds (mainly in the form of quartz and cristobalite) in the ashes. Potassium was proven to cause surface melting of a eutectic potassium-silica compound, restraining carbon emissions from burning $\mathrm{RH}$ and hence leading to the formation of fixed black carbonaceous matter and accelerating the crystallization of amorphous silica to form cristobalite.

Acid-leaching pretreatment can effectively remove the concentration of alkali metal impurities in RH. An amorphous silica with purity above $96 \%$ is yielded from RH by $1 \mathrm{~N}$ hydrochloric acid leaching followed by calcination at $600{ }^{\circ} \mathrm{C}$ for $2 \mathrm{~h}$. Sulfuric acid and nitric acid have comparable rinsing performance to hydrochloric acid. The acid treatment increases the crystallization temperature of RHA silica to $1200{ }^{\circ} \mathrm{C}$ and retains the amorphous state for $2.5 \mathrm{~h}$.

Water-leaching pretreatment also exerted sound performance in rinsing off the alkali metal impurities. A reactive amorphous silica with a concentration of $94 \%$ is yielded via water-leaching pretreatment for $2.5 \mathrm{~h}$ and pyrolysis of $600{ }^{\circ} \mathrm{C}$ for $2 \mathrm{~h}$. Moreover, water-leaching pretreatment on $\mathrm{RH}$ for $2.5 \mathrm{~h}$ could maintain the amorphous state of silica at $900{ }^{\circ} \mathrm{C}$ for $7 \mathrm{~h}$.

The compressive strength of the acid-leaching-pretreated, RHA-incorporated paste is $48.1 \%$ higher than that of the control paste. The RH with boiling-water-leaching pretreatment for $2.5 \mathrm{~h}$ yields ash-blended paste having a compressive strength of $64.8 \mathrm{MPa}$, which was $42.4 \%$ higher than that of the control paste. Expanding the water-leaching duration did not obviously improve the pozzolanic reactivity of RHA. Thus, $2.5 \mathrm{~h}$ was an acceptable duration for boiling-water-leaching treatment on $\mathrm{RH}$ to achieve a highly reactive pozzolana. In addition, the boiling-water-leaching-pretreated RHA silica has a comparable pozzolanic performance at improving the cement hydration to the acid-pretreated one, as reflected by the calculation results of chemically bound water content.

In summary, the boiling-water-leaching pretreatment is slightly inferior to the hydrochloric-acid-leaching pretreatment at improving the thermal stability and removing the metal impurities of RHA silica. However, the boiling-water-leaching treatment is superior to the acid-leaching pretreatment in using an industrial cooling water system and hence reducing the investment in process technology and sophisticated equipment. Furthermore, the amorphous silica obtained under the water-leaching-pyrolysis treatment achieves a biomass amorphous silica with high purity and large surface area, and hence can be produced at a large scale as a highly reactive 
pozzolana for applying in the production of high-strength cement and concrete. Thus, this study is of great significance for the extension of RHA in the practical application of cement engineering.

Author Contributions: W.X. designed the experiments and wrote the paper. J.W., J.C., B.Z., P.X. and J.R. performed the experiments and analyzed the data. Q.Y. supervised the project.

Funding: This research was funded by the National Natural Science Foundation of China (Grant No. 51408363), the China Postdoctoral Science Foundation (Grant Nos. 2017M610526 and 2018T110869) and the Fundamental Research Funds for the Central Universities (Grant No. 2018MS08).

Acknowledgments: The authors thank the reviewers for their valuable comments and suggestions concerning our manuscript.

Conflicts of Interest: The authors declare no conflict of interest.

\section{References}

1. Pode, R. Potential applications of rice husk ash waste from rice husk biomass power plant. Renew. Sustain. Energy Rev. 2016, 53, 1468-1485. [CrossRef]

2. Prasara-A, J.; Gheewala, S.H. Sustainable utilization of rice husk ash from power plants: A review. J. Clean. Prod. 2017, 167, 1020-1028. [CrossRef]

3. Sun, L.; Gong, K. Silica-Based Materials from Rice Husks and Their Applications. Ind. Eng. Chem. Res. 2001, 40, 5861-5877. [CrossRef]

4. Roselló, J.; Soriano, L.; Santamarina, M.P.; Akasaki, J.L.; Monzó, J.; Payá, J. Rice straw ash: A potential pozzolanic supplementary material for cementing systems. Ind. Crops Prod. 2017, 103, 39-50. [CrossRef]

5. $\mathrm{Xu}, \mathrm{W}$; Lo, T.Y.; Memon, S.A. Microstructure and reactivity of rich husk ash. Constr. Build. Mater. 2012, 29, 541-547. [CrossRef]

6. Fapohunda, C.; Akinbile, B.; Shittu, A. Structure and properties of mortar and concrete with rice husk ash as partial replacement of ordinary Portland cement-A review. Int. J. Sustain. Built Environ. 2017, 6, 675-692. [CrossRef]

7. Sutas, J.; Mana, A.; Pitak, L. Effect of Rice Husk and Rice Husk Ash to Properties of Bricks. Procedia Eng. 2012, 32, 1061-1067. [CrossRef]

8. Pongdong, W.; Kummerlöwe, C.; Vennemann, N.; Thitithammawong, A.; Nakason, C. Property correlations for dynamically cured rice husk ash filled epoxidized natural rubber/thermoplastic polyurethane blends: Influences of RHA loading. Polym. Test. 2016, 53, 245-256. [CrossRef]

9. Chiang, K.Y.; Chou, P.H.; Hua, C.R.; Chien, K.L.; Cheeseman, C. Lightweight bricks manufactured from water treatment sludge and rice husks. J. Hazard. Mater. 2009, 171, 76-82. [CrossRef] [PubMed]

10. Feng, Q.; Chen, K.; Ma, D.; Lin, H.; Liu, Z.; Qin, S.; Luo, Y. Synthesis of high specific surface area silica aerogel from rice husk ash via ambient pressure drying. Colloid Surf. A 2018, 539, 399-406. [CrossRef]

11. Soltani, N.; Bahrami, A.; Pech-Canul, M.I.; González, L.A. Review on the physicochemical treatments of rice husk for production of advanced materials. Chem. Eng. J. 2015, 264, 899-935. [CrossRef]

12. Menya, E.; Olupot, P.W.; Storz, H.; Lubwama, M.; Kiros, Y. Production and performance of activated carbon from rice husks for removal of natural organic matter from water: A review. Chem. Eng. Res. Des. 2018, 129, 271-296. [CrossRef]

13. Yu, K.; Li, J.; Qi, H.; Liang, C. High-capacity activated carbon anode material for lithium-ion batteries prepared from rice husk by a facile method. Diam. Relat. Mater. 2018, 86, 139-145. [CrossRef]

14. Zhang, S.; Zhu, S.; Zhang, H.; Chen, T.; Xiong, Y. Catalytic fast pyrolysis of rice husk: Effect of coupling leaching with torrefaction pretreatment. J. Anal. Appl. Pyrolysis 2018, 133, 91-96. [CrossRef]

15. Wang, Q.; Zhu, X.; Liu, Y.; Fang, Y.; Zhou, X.; Bao, J. Rice husk-derived hard carbons as high-performance anode materials for sodium-ion batteries. Carbon 2018, 127, 658-666. [CrossRef]

16. Chen, S.Y.; Chou, P.F.; Chan, W.K.; Lin, H.M. Preparation and characterization of mesoporous bioactive glass from agricultural waste rice husk for targeted anticancer drug delivery. Ceram. Int. 2017, 43, 2239-2245. [CrossRef]

17. Shen, $\mathrm{Y}$; $\mathrm{Fu}, \mathrm{Y}$. $\mathrm{KOH}$-activated rice husk char via $\mathrm{CO}_{2}$ pyrolysis for phenol adsorption. Mater. Today 2018, 9, 397-405. [CrossRef] 
18. Wei, J.; Meyer, C. Utilization of rice husk ash in green natural fiber-reinforced cement composites: Mitigating degradation of sisal fiber. Cem. Concr. Res. 2016, 81, 94-111. [CrossRef]

19. Allahbakhsh, A.; Noei Khodabadi, F.; Hosseini, F.S.; Haghighi, A.H. 3-Aminopropyl-triethoxysilane-functionalized rice husk and rice husk ash reinforced polyamide 6/graphene oxide sustainable nanocomposites. Eur. Polym. J. 2017, 94, 417-430. [CrossRef]

20. Rhee, I.; Lee, J.S.; Kim, J.H.; Kim, Y.A. Thermal performance, freeze-and-thaw resistance, and bond strength of cement mortar using rice husk-derived graphene. Constr. Build. Mater. 2017, 146, 350-359. [CrossRef]

21. Ziegler, D.; Formia, A.; Tulliani, J.M.; Palmero, P. Environmentally-friendly dense and porous geopolymers using fly ash and rice husk ash as raw materials. Materials 2016, 9, 466. [CrossRef] [PubMed]

22. Karim, R.M.; Hossain, M.M.; Khan, N.M.; Zain, F.M.; Jamil, M.; Lai, C.F. On the Utilization of Pozzolanic Wastes as an Alternative Resource of Cement. Materials 2014, 7, 7809-7827. [CrossRef] [PubMed]

23. Saad, S.A.; Nuruddin, M.F.; Shafiq, N.; Ali, M. The Effect of Incineration Temperature to the Chemical and Physical Properties of Ultrafine Treated Rice Husk Ash (UFTRHA) as Supplementary Cementing Material (SCM). Procedia Eng. 2016, 148, 163-167. [CrossRef]

24. Bakar, R.A.; Yahya, R.; Gan, S.N. Production of High Purity Amorphous Silica from Rice Husk. Procedia Chem. 2016, 19, 189-195. [CrossRef]

25. Hu, S.; Xiang, J.; Sun, L.; Xu, M.; Qiu, J.; Fu, P. Characterization of char from rapid pyrolysis of rice husk. Fuel Process. Technol. 2008, 89, 1096-1105. [CrossRef]

26. Della, V.P.; Kühn, I.; Hotza, D. Rice husk ash as an alternate source for active silica production. Mater. Lett. 2002, 57, 818-821. [CrossRef]

27. Danewalia, S.S.; Sharma, G.; Thakur, S.; Singh, K. Agricultural wastes as a resource of raw materials for developing low-dielectric glass-ceramics. Sci. Rep. 2016, 6, 24617. [CrossRef] [PubMed]

28. Krishnarao, R.V.; Subrahmanyam, J.; Jagadish, K.T. Studies on the formation of black particles in rice husk silica ash. J. Eur. Ceram. Soc. 2001, 21, 99-104. [CrossRef]

29. Shen, J.; Liu, X.; Zhu, S.; Zhang, H.; Tan, J. Effects of calcination parameters on the silica phase of original and leached rice husk ash. Mater. Lett. 2011, 65, 1179-1183. [CrossRef]

30. Gregg, S.J.; Sing, K.S.W. Adsorption, Surface Area and Porosity; Wiley: New York, NY, USA, 1982.

31. Johar, N.; Ahmad, I.; Dufresne, A. Extraction, preparation and characterization of cellulose fibres and nanocrystals from rice husk. Ind. Crops Prod. 2012, 37, 93-99. [CrossRef]

32. Yeh, S.K.; Hsieh, C.C.; Chang, H.C.; Yen, C.C.C.; Chang, Y.C. Synergistic effect of coupling agents and fiber treatments on mechanical properties and moisture absorption of polypropylene-rice husk composites and their foam. Compos. Appl. Sci. Manuf. 2015, 68, 313-322. [CrossRef]

33. Tran, T.P.T.; Bénézet, J.C.; Bergeret, A. Rice and Einkorn wheat husks reinforced poly(lactic acid) (PLA) biocomposites: Effects of alkaline and silane surface treatments of husks. Ind. Crops Prod. 2014, 58, 111-124. [CrossRef]

34. Das, A.M.; Ali, A.A.; Hazarika, M.P. Synthesis and characterization of cellulose acetate from rice husk: Eco-friendly condition. Carbohydr. Polym. 2014, 112, 342-349. [CrossRef] [PubMed]

35. Costa, J.A.S.; Garcia, A.C.F.S.; Santos, D.O.; Sarmento, V.H.V.; De Mesquita, M.E.; Romão, L.P.C. Applications of inorganic-organic mesoporous materials constructed by self-assembly processes for removal of benzo[k]fluoranthene and benzo[b]fluoranthene. J. Sol-Gel Sci. Technol. 2015, 75, 495-507. [CrossRef]

36. Santos, D.O.; De Lourdes Nascimento Santos, M.; Costa, J.A.S.; De Jesus, R.A.; Navickiene, S.; Sussuchi, E.M.; De Mesquita, M.E. Investigating the potential of functionalized MCM-41 on adsorption of Remazol Red dye. Environ. Sci. Pollut. Res. 2013, 20, 5028-5035. [CrossRef] [PubMed]

37. Xu, W.; Lo, T.Y.; Wang, W.; Ouyang, D.; Wang, P.; Xing, F. Pozzolanic Reactivity of Silica Fume and Ground Rice Husk Ash as Reactive Silica in a Cementitious System: A Comparative Study. Materials 2016, 9, 146. [CrossRef] [PubMed]

38. Santana Costa, J.A.; Paranhos, C.M. Systematic evaluation of amorphous silica production from rice husk ashes. J. Clean. Prod. 2018, 192, 688-697. [CrossRef]

39. Ji, Y.; Jong, H.C. Effects of densified silica fume on microstructure and compressive strength of blended cement pastes. Cem. Concr. Res. 2003, 33, 1543-1548. [CrossRef]

40. Sinthaworn, S.; Nimityongskul, P. Quick monitoring of pozzolanic reactivity of waste ashes. Waste Manag. 2009, 29, 1526-1531. [CrossRef] [PubMed] 
41. Garg, N.; Skibsted, J. Pozzolanic reactivity of a calcined interstratified illite/smectite (70/30) clay. Cem. Concr. Res. 2016, 79, 101-111. [CrossRef]

42. Shen, D.S.; Qiu, Q.Y. Systematization of physical order parameters of fly ash. J. Chin. Ceram. Soc. 1992, 20, 302-308. [CrossRef] 